\title{
Controlled light and temperature induced valence tautomerism in Cobalt-o-Dioxolene complex
}

\author{
Ludmila Leroy $^{1}$, Thiago M. Francisco ${ }^{1}$, Helena J. Shepherd ${ }^{2}$, Mark R. Warren ${ }^{3}$, Lucy K. Saunders ${ }^{3}$, David A. \\ Shultz ${ }^{4}$, Paul R. Raithby ${ }^{5}$, Carlos B. Pinheiro ${ }^{1 *}$ \\ ${ }^{1}$ Physics department, Universidade Federal de Minas Gerais, Belo Horizonte, 31270-901, Brazil \\ ${ }^{2}$ School of Physical Sciences, University of Kent, Canterbury CT2 7NZ, United Kingdom \\ ${ }^{3}$ Diamond Light Source, Ltd., Harwell Science \& Innovation Campus, Didcot OX11 0DE, United Kingdom \\ ${ }^{4}$ Department of Chemistry, North Carolina State University, Raleigh, North Carolina 27695, United States \\ ${ }^{5}$ Department of Chemistry, University of Bath, Bath BA2 7AY, United Kingdom
}

*cbpinheiro@ufmg.br

\section{Supporting Information}

\section{X-ray diffraction experiments description}

Different single crystals of $\left[\mathrm{Co}(\text { diox })_{2}(4-\mathrm{CN}-\mathrm{py})_{2}\right] \cdot$ benzene complex (diox $=3,5$-di-t-butylsemiquinonate, (SQ $\left.{ }^{-}\right)$and/or 3,5-di-t-butylcatecholate $\left(\mathrm{Cat}^{2-}\right)$ radical; 4-CN-py $=4$-cyano-pyridine) were probed in X-ray diffraction experiments using hard X-rays. The experiments aimed for assessing X-ray irradiation effects on the valence tautomerism interconversion (VTI) at $30 \mathrm{~K}$, temperature dependent VTI and light induced VTI using blue and red laser diodes. Single crystal X-ray diffraction (SCXRD) data were collected at I19 - the small-molecule single-crystal diffraction beamline at Diamond Light Source, which has a flux of about $10^{10}$ photons s${ }^{-1}$, distributed over a spot of $0.2 \times 0.2 \mathrm{~mm}^{2}-$ using $0.4859 \AA$ radiation $(25516.4 \mathrm{eV})$. A commercially available open-flow He cryostat apparatus (n-HeliX, Oxford Cryosystems), with stability better than $\pm 0.3 \mathrm{~K}$, was used to control the sample temperature. Sample illumination was achieved using blue (450nm) and red (660nm) light from laser diodes (L450P1600MM and L660P120, ThorLabs). Many different single crystal samples suitable for X-ray diffraction experiments were mounted in a caption loop and investigated. Experiments with three different samples turned out to produce consistent data for the structure analysis under hard X-ray irradiation and light illumination. A summary of these experimental and sample details can be found at Table S1.

In the xrayinduce_1 experiment (see Table S1), the effect of the X-ray irradiation on the VTI rates was investigated, aiming for determining an attenuation regime in which VTI was negligible. Crystal 1 was fast cooled from $290 \mathrm{~K}$ down to $30 \mathrm{~K}$, and seven (7) SCXRD runs at $30 \mathrm{~K}$ were performed for various attenuation values. The four (4) first experiments were undertaken with transmission factor of $25 \%$. Then the sample was left under full beam transmission for 30 minutes and XRD was subsequently measured with $25 \%$ transmission. Finally, two (2) more SCXRD runs with transmission factor of $60 \%$ were performed. This experiment was used to look for the best experimental condition to avoid the tautomeric interconversion from ground state $l s-\mathrm{Co}^{\mathrm{III}}$ into the metastable $h s-\mathrm{Co}^{\mathrm{II}}$ due to hard X-rays irradiation.

For the experiment named lightinduce_3 and tempinduce_1, (see Table S1) another crystal was used. Crystal 2 was first fast cooled to $30 \mathrm{~K}$ and SCXRD data before illumination was acquired at run 1 . The sample was kept at $30 \mathrm{~K}$ and illuminated with a laser diode of $450 \mathrm{~nm}$ light for the times described in Table S1. The sample was rotated while being illuminated by the diode, hutch lights were maintained off throughout the whole experiment. Laser diodes were switched off during XRD data collection (0.4s per image, 635 images per omega). After a plateau in the VTI rate was achieved at run 5, the temperature dependent VTI interconversion was evaluated from runs 6 to 20 , going from $30 \mathrm{~K}$ to $300 \mathrm{~K}$, and back to $30 \mathrm{~K}$ at run 21 .

Lastly, experiment lightinduce_5 was performed with crystal 3, a smaller crystal which required larger transmission values for the XRD experiment. At this experiment, the VTI induced by X-rays (runs 1 and 2) and $450 \mathrm{~nm}$ light (runs 3 to 6) was assessed until reaching the interconversion plateau, and the de-excitation of hs-Co ${ }^{\mathrm{II}}$ metastable states was probed using $660 \mathrm{~nm}$ laser diode (runs 7 to 9). 
Table S1: Run map and experiment details for the X-ray diffraction measurements for the 3 crystals reported.

\begin{tabular}{|c|c|c|c|c|c|c|c|c|c|c|c|c|c|}
\hline 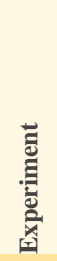 & 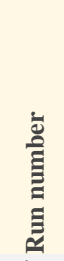 & 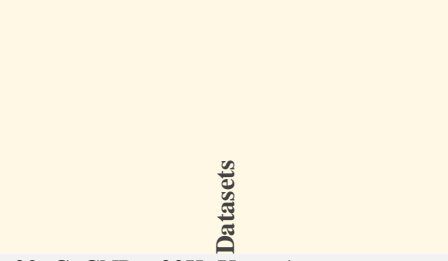 & 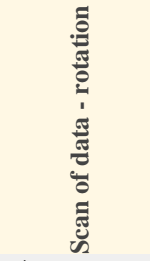 & 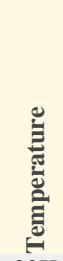 & 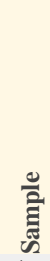 & 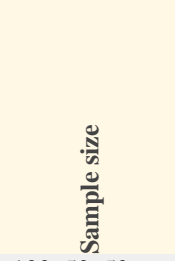 & 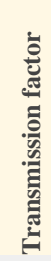 & 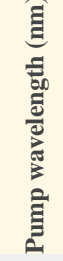 & 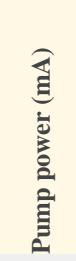 & 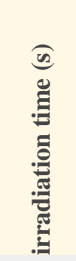 & 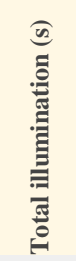 & 苞 & $\bar{\Xi}$ \\
\hline \multirow{7}{*}{ 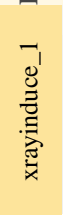 } & 1 & 02_CoCNPy_30K_Xray_1 & $4 \mathrm{x}$ omega & $30 \mathrm{~K}$ & 1 & $100 \times 50 \times 50$ & 25 & & & & & 3.9 & 0.042 \\
\hline & 2 & 02_CoCNPy_30K_Xray_2 & $4 \mathrm{x}$ omega & $30 \mathrm{~K}$ & 1 & $100 \times 50 \times 50$ & 25 & & & & & 3.8 & 0.042 \\
\hline & 3 & 02_CoCNPy_30K_Xray_3 & $4 \mathrm{x}$ omega & $30 \mathrm{~K}$ & 1 & $100 \times 50 \times 50$ & 25 & & & & & 3.9 & 0.043 \\
\hline & 4 & 02_CoCNPy_30K_Xray_4 & $4 \mathrm{x}$ omega & $30 \mathrm{~K}$ & 1 & $100 \times 50 \times 50$ & 25 & & & & & 4.0 & 0.044 \\
\hline & 5 & 03_CoCNPy_30K_Xray_1 & $4 \mathrm{x}$ omega & $30 \mathrm{~K}$ & 1 & $100 \times 50 \times 50$ & 25 & & & & & 4.2 & 0.044 \\
\hline & 6 & 04_CoCNPy_30K_Xray_1 & $4 \mathrm{x}$ omega & $30 \mathrm{~K}$ & 1 & $100 \times 50 \times 50$ & 60 & & & & & 3.5 & 0.042 \\
\hline & 7 & 04_CoCNPy_30K_Xray_2 & $4 \mathrm{x}$ omega & $30 \mathrm{~K}$ & 1 & $100 \times 50 \times 50$ & 60 & & & & & 3.6 & 0.041 \\
\hline \multirow{21}{*}{ 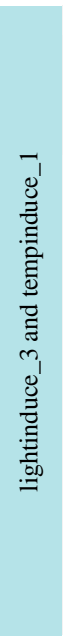 } & 1 & 38_CoCNPy_30K_GS & $4 \mathrm{x}$ omega & $30 \mathrm{~K}$ & 2 & $300 \times 100 \times 100$ & 5 & & & & & 3.4 & 0.052 \\
\hline & 2 & 39_CoCNPy_30K_450nm_300s_rotate & $4 \mathrm{x}$ omega & $30 \mathrm{~K}$ & 2 & $300 \times 100 \times 100$ & 5 & 450 & 28.84 & 300 & 300 & 5.0 & 0.076 \\
\hline & 3 & 40_CoCNPy_30K_450nm_1800s_rotate & $4 \mathrm{x}$ omega & $30 \mathrm{~K}$ & 2 & $300 \times 100 \times 100$ & 5 & 450 & 28.84 & 1800 & 2100 & 5.2 & 0.075 \\
\hline & 4 & 41_CoCNPy_30K_450nm_1200s_rotate & $4 \mathrm{x}$ omega & $30 \mathrm{~K}$ & 2 & $300 \times 100 \times 100$ & 5 & 450 & 28.84 & 1200 & 3300 & 5.1 & 0.072 \\
\hline & 5 & 42_CoCNPy_30K_450nm_4500s_rotate & $4 \mathrm{x}$ omega & $30 \mathrm{~K}$ & 2 & $300 \times 100 \times 100$ & 5 & 450 & 28.84 & 1200 & 4500 & 5.0 & 0.070 \\
\hline & 6 & 43_CoCNPy_TS_30K & $5 \mathrm{x}$ same run & 30 & 2 & $300 \times 100 \times 100$ & 5 & & & & & 6.6 & 0.093 \\
\hline & 7 & 43_CoCNPy_TS_35K & $5 \mathrm{x}$ same run & 35 & 2 & $300 \times 100 \times 100$ & 5 & & & & & 6.0 & 0.088 \\
\hline & 8 & 43_CoCNPy_TS_40K & $5 \mathrm{x}$ same run & 40 & 2 & $300 \times 100 \times 100$ & 5 & & & & & 6.0 & 0.092 \\
\hline & 9 & 43_CoCNPy_TS_45K & $5 \mathrm{x}$ same run & 45 & 2 & $300 \times 100 \times 100$ & 5 & & & & & 6.8 & 0.096 \\
\hline & 10 & 43_CoCNPy_TS_50K & $5 \mathrm{x}$ same run & 50 & 2 & $300 \times 100 \times 100$ & 5 & & & & & 5.6 & 0.084 \\
\hline & 11 & 43_CoCNPy_TS_55K & $5 \mathrm{x}$ same run & 55 & 2 & $300 \times 100 \times 100$ & 5 & & & & & 4.6 & 0.067 \\
\hline & 12 & 43_CoCNPy_TS_60K & $5 \mathrm{x}$ same run & 60 & 2 & $300 \times 100 \times 100$ & 5 & & & & & 4.5 & 0.067 \\
\hline & 13 & 43_CoCNPy_TS_70K & $5 \mathrm{x}$ same run & 70 & 2 & $300 \times 100 \times 100$ & 5 & & & & & 4.5 & 0.071 \\
\hline & 14 & 43_CoCNPy_TS_80K & $5 x$ same run & 80 & 2 & $300 \times 100 \times 100$ & 5 & & & & & 4.6 & 0.073 \\
\hline & 15 & 43_CoCNPy_TS_90K & $5 \mathrm{x}$ same run & 90 & 2 & $300 \times 100 \times 100$ & 5 & & & & & 4.6 & 0.074 \\
\hline & 16 & 43_CoCNPy_TS_100K & $5 \mathrm{x}$ same run & 100 & 2 & $300 \times 100 \times 100$ & 5 & & & & & 4.8 & 0.074 \\
\hline & 17 & 43_CoCNPy_TS_150K & $5 \mathrm{x}$ same run & 150 & 2 & $300 \times 100 \times 100$ & 5 & & & & & 5.3 & 0.078 \\
\hline & 18 & 43_CoCNPy_TS_200K & $5 \mathrm{x}$ same run & 200 & 2 & $300 \times 100 \times 100$ & 5 & & & & & 5.9 & 0.092 \\
\hline & 19 & 43_CoCNPy_TS_250K & $5 \mathrm{x}$ same run & 250 & 2 & $300 \times 100 \times 100$ & 5 & & & & & 6.4 & 0.103 \\
\hline & 20 & 43_CoCNPy_TS_300K & $5 \mathrm{x}$ same run & 300 & 2 & $300 \times 100 \times 100$ & 5 & & & & & 7.8 & 0.116 \\
\hline & 21 & 44_CoCNPy_30K_GS_after_Temp & $4 \mathrm{x}$ omega & 30 & 2 & $300 \times 100 \times 100$ & 5 & & & & & 3.8 & 0.058 \\
\hline \multirow{9}{*}{ 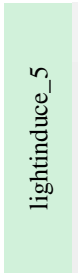 } & 1 & 66a_CoCNPy_30K_GS & $1 \mathrm{x}$ omega & $30 \mathrm{~K}$ & 3 & $80 \times 80 \times 40$ & 15 & & & & & 7.5 & 0.117 \\
\hline & 2 & 66b_CoCNPy_30K_GS & 1x omega & $30 \mathrm{~K}$ & 3 & $80 \times 80 \times 40$ & 15 & & & & & 7.6 & 0.099 \\
\hline & 3 & 67_CoCNPy_30K_450nm_300s & 1x omega & $30 \mathrm{~K}$ & 3 & $80 \times 80 \times 40$ & 15 & 450 & 25.47 & 300 & 300 & 7.4 & 0.143 \\
\hline & 4 & 68_CoCNPy_30K_450nm_600s & $1 \mathrm{x}$ omega & $30 \mathrm{~K}$ & 3 & $80 \times 80 \times 40$ & 15 & 450 & 25.47 & 300 & 600 & 11.0 & 0.131 \\
\hline & 5 & 69_CoCNPy_30K_450nm_1800s & $1 \mathrm{x}$ omega & $30 \mathrm{~K}$ & 3 & $80 \times 80 \times 40$ & 15 & 450 & 25.47 & 1200 & 1800 & 10.8 & 0.135 \\
\hline & 6 & 70_CoCNPy_30K_450nm_1800s & $4 \mathrm{x}$ omega & $30 \mathrm{~K}$ & 3 & $80 \times 80 \times 40$ & 15 & 450 & 25.47 & 1200 & 1800 & 8.43 & 0.087 \\
\hline & 7 & 71_CoCNPy_30K_660nm_300s & $1 \mathrm{x}$ omega & $30 \mathrm{~K}$ & 3 & $80 \times 80 \times 40$ & 15 & 660 & 120 & 300 & 300 & 7.4 & 0.128 \\
\hline & 8 & 72_CoCNPy_30K_660nm_600s & 1x omega & $30 \mathrm{~K}$ & 3 & $80 \times 80 \times 40$ & 15 & 660 & 120 & 300 & 600 & 9.4 & 0.129 \\
\hline & 9 & 73_CoCNPy_30K_660nm_1800s & 1x omega & $30 \mathrm{~K}$ & 3 & $80 \times 80 \times 40$ & 15 & 660 & 120 & 1200 & 1800 & 9.4 & 0.130 \\
\hline
\end{tabular}




\section{Data reduction and structure refinement statistics}

For all experiments and runs described in Table S1, single crystal X-ray diffraction data integration and scaling of the reflection intensities were performed with the using $\mathrm{XDS}^{1}$, in which we were not able to optimize processing parameters for small molecule crystal any further. However, data quality and consistency indicators were very satisfactory (see Figures S1, S2 and S3). The software was recurrently recruited for systematic data processing of datasets with the aid of python scripts, available upon request. Structure was solved by direct methods using SHELXT ${ }^{2}$. Refinements were performed using SHELXL ${ }^{3}$ based on $F^{2}$ through full-matrix least-squares routine. Hydrogen atoms were located in Fourier difference maps and included as fixed contributions according to the riding $\operatorname{model}^{4}(\mathrm{C}-\mathrm{H}$ and $\mathrm{N}-\mathrm{H}=0.97 \AA$ and $U_{\text {iso }}(\mathrm{H})=1.2 U_{\text {eq }}(\mathrm{C}$ or $\mathrm{N})$ for methylene and aromatic groups and carbon atoms $)$. All non-hydrogen atoms were refined with anisotropic atomic displacement parameters.

The evolution of I/sigma and $\mathrm{CC} 1 / 2^{6}$ during each experiment for the 3 different crystals used in this work are shown in Figures S1, S2 and S3, as well as the evolution of the refinement parameter, R1 ${ }^{7}$. Each dataset-point in the graphs of Figure S1, S2 and S3 corresponds to one run (Table S1).

Particularly, the X-ray diffraction dataset of the lightinduce 5 experiments were obtained from a crystal which was undergoing valence tautomerism interconversion induced by $\overline{\mathrm{X}}$-rays. Therefore, each group of images from the rotation around different degrees of freedom of the goniometer had to be processed separately in order to account for the structural changes accordingly. This led to data sets with reduced completeness that did not compromise the refinements i.e. in did not impact the interatomic distances used to compute metastable molar fractions.

Information regarding crystal data, measurement and refinement data, for crystal samples 1,2 and 3 are shown in Table S2. CCDC $^{5}$ CIF files 2058451-2058453 contain the complete supplementary crystallographic data for three representative experiments performed and for the different crystals in this work. They can be obtained free of charge from The Cambridge Crystallographic Data Centre via https://www.ccdc.cam.ac.uk/structures/. The 2058451 and 2058452 CIF files reported ERROR B (s.u. on the betangle is Too Large) which has to do with XDS data reduction software, in which we were not able to optimize processing parameters for small molecule crystal any further. In the 2058453 the reported ERROR A (diffrn_measured_fraction_theta_full value Low) is due to the fact that along the experiment, we measured many partial data sets from a crystal which was undergoing the interconversion $l s-\mathrm{Co}^{\mathrm{III}} \Leftrightarrow h s^{-}$

$\mathrm{Co}^{\mathrm{II}}$ induced by the X-rays irradiation. Therefore, each group of images from the rotation around different degrees of freedom of the goniometer had to be processed separately in order to account for the structural changes properly. The characterization of the complete phase transition is discussed in the manuscript however we decided to not touch the raw partial data file and deposit it as it is. 
Table S2: SCXRD data and structure refinement statistics for the 3 crystals investigated at $30 \mathrm{~K}$.

\begin{tabular}{|c|c|c|c|}
\hline Crystal number & 1 & 2 & 3 \\
\hline Identification code & 02_cocnpy_30k & 38_cocnpy_30k & 66a_cocnpy_30k_GS \\
\hline Empirical formula & C52 H60 Co N4 O4 & $\mathrm{C} 52 \mathrm{H} 60 \mathrm{Co} \mathrm{N} 4 \mathrm{O} 4$ & C52 H60 Co N4 O4 \\
\hline Formula weight & 863.97 & 863.97 & 863.97 \\
\hline Temperature & $30.15 \mathrm{~K}$ & $30.15 \mathrm{~K}$ & $30.15 \mathrm{~K}$ \\
\hline Wavelength & $0.4859 \AA$ & $0.4859 \AA$ & $0.4859 \AA$ \\
\hline Crystal system & Monoclinic & Monoclinic & Monoclinic \\
\hline Space group & P $121 / \mathrm{c} 1$ & $\mathrm{P} 121 / \mathrm{c} 1$ & $\mathrm{P} 121 / \mathrm{c} 1$ \\
\hline \multirow[t]{4}{*}{ Unit cell dimensions } & $a=14.96(2) \AA$ & $a=14.90(3) \AA$ & $a=15.01(6) \AA$ \\
\hline & $\mathrm{b}=22.08(2) \AA$ & $\mathrm{b}=22.07(3) \AA$ & $\mathrm{b}=22.16(7) \AA$ \\
\hline & $c=7.303(7) \AA$ & $c=7.297(8) \AA$ & $c=7.34(3) \AA$ \\
\hline & $\beta=97.33(8)^{\circ}$. & $\beta=97.24(6)^{\circ}$ & $\beta=97.19(4)^{\circ}$ \\
\hline Volume & $2393(5) \AA^{3}$ & $2381(6) \AA^{3}$ & $2422(15) \AA^{3}$ \\
\hline $\mathrm{Z}$ & 2 & 2 & 2 \\
\hline Density (calculated) & $1.199 \mathrm{Mg} / \mathrm{m}^{3}$ & $1.205 \mathrm{Mg} / \mathrm{m}^{3}$ & $1.185 \mathrm{Mg} / \mathrm{m}^{3}$ \\
\hline Absorption coefficient & $0.406 \mathrm{~mm}^{-1}$ & $0.408 \mathrm{~mm}^{-1}$ & $0.401 \mathrm{~mm}^{-1}$ \\
\hline $\mathrm{F}(000)$ & 918 & 918 & 918 \\
\hline Crystal size & $0.1 \times 0.05 \times 0.05 \mathrm{~mm}^{3}$ & $0.3 \times 0.1 \times 0.1 \mathrm{~mm}^{3}$ & $0.08 \times 0.04 \times 0.04 \mathrm{~mm}^{3}$ \\
\hline Theta range for data collection & 0.938 to $17.679^{\circ}$. & 1.133 to $17.679^{\circ}$. & 1.566 to $17.678^{\circ}$. \\
\hline Index ranges & $\begin{array}{l}-18<=\mathrm{h}<=17, \\
-27<=\mathrm{k}<=27, \\
-9<=1<=7\end{array}$ & $\begin{array}{l}-18<=\mathrm{h}<=18, \\
-27<=\mathrm{k}<=23, \\
-9<=1<=9\end{array}$ & $\begin{array}{l}-18<=\mathrm{h}<=9, \\
-23<=\mathrm{k}<=23, \\
-7<=1<=8\end{array}$ \\
\hline Reflections collected & 30071 & 29633 & 6601 \\
\hline Independent reflections & $4889[\mathrm{R}($ int $)=0.0448]$ & $4865[\mathrm{R}(\mathrm{int})=0.0414]$ & $3328[\mathrm{R}(\mathrm{int})=0.0673]$ \\
\hline Completeness to theta $=16.950^{\circ}$ & $100.0 \%$ & $99.9 \%$ & $68.7 \%$ \\
\hline Refinement method & $\begin{array}{l}\text { Full-matrix least-squares } \\
\text { on } \mathrm{F}^{2}\end{array}$ & $\begin{array}{l}\text { Full-matrix least-squares } \\
\text { on } \mathrm{F}^{2}\end{array}$ & $\begin{array}{l}\text { Full-matrix least-squares } \\
\text { on } \mathrm{F}^{2}\end{array}$ \\
\hline Data / restraints / parameters & $4889 / 36 / 271$ & $4865 / 36 / 271$ & $3328 / 36 / 271$ \\
\hline Goodness-of-fit on $\mathrm{F}^{2}$ & 1.023 & 1.062 & 0.912 \\
\hline Final $R$ indices $[I>2 \operatorname{sigma}(I)]$ & $\begin{array}{l}\mathrm{R} 1=0.0340 \\
\mathrm{wR} 2=0.0853\end{array}$ & $\begin{array}{l}\mathrm{R} 1=0.0418 \\
\mathrm{wR} 2=0.1115\end{array}$ & $\begin{array}{l}\mathrm{R} 1=0.0820 \\
\mathrm{wR} 2=0.2139\end{array}$ \\
\hline $\mathrm{R}$ indices (all data) & $\begin{array}{l}\mathrm{R} 1=0.0409 \\
\mathrm{wR} 2=0.0893\end{array}$ & $\begin{array}{l}\mathrm{R} 1=0.0465 \\
\mathrm{wR} 2=0.1152\end{array}$ & $\begin{array}{l}\mathrm{R} 1=0.1186 \\
\mathrm{wR} 2=0.2555\end{array}$ \\
\hline Largest diff. peak and hole & 0.443 and -0.347 e. $\AA^{-3}$ & 1.514 and $-0.628 \mathrm{e} \cdot \AA^{-3}$ & 1.721 and -1.025 e. $\AA^{-3}$ \\
\hline CCDC code & 2058451 & 2058452 & 2058453 \\
\hline
\end{tabular}


FIGURE S1: Crystal 1, experiment xrayinduce_1: VT induced by X-rays for different attenuations. The evolution of the statistics of the X-ray diffraction data and refinement for the crystals 1, 2 and 3. (a) I/sigma, (b) cc1/2, (c) r1.
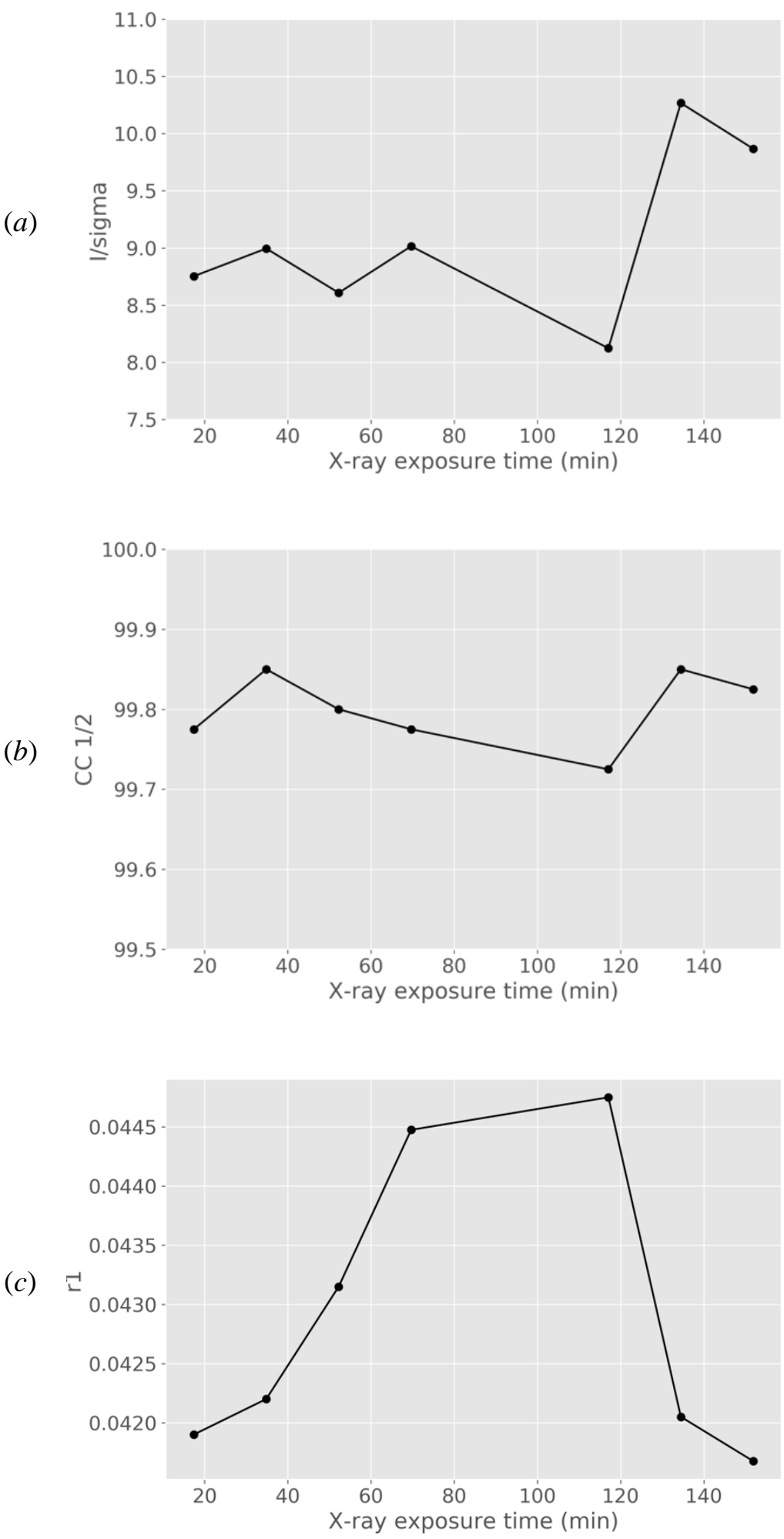
FIGURE S2: Crystal 2, experiment lightinduce_3 and tempinduce_1: VT induced by blue $450 \mathrm{~nm}$ light and sequentially by temperature increase. The evolution of the statistics of the X-ray diffraction data and refinement for the crystals 1, 2 and 3. (a) I/sigma, (b) cc1/2, (c) r1.

(a)

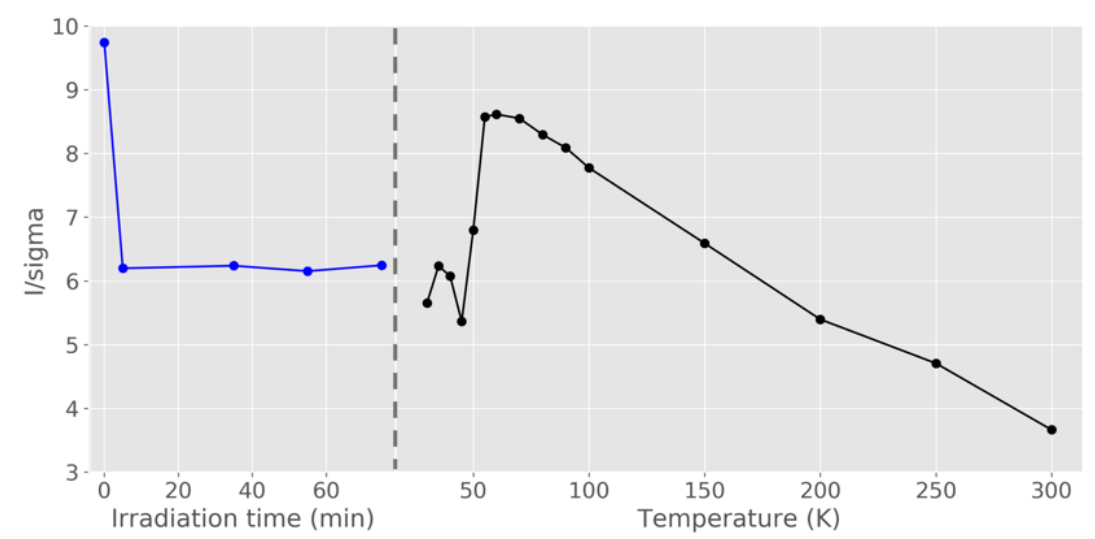

(b)

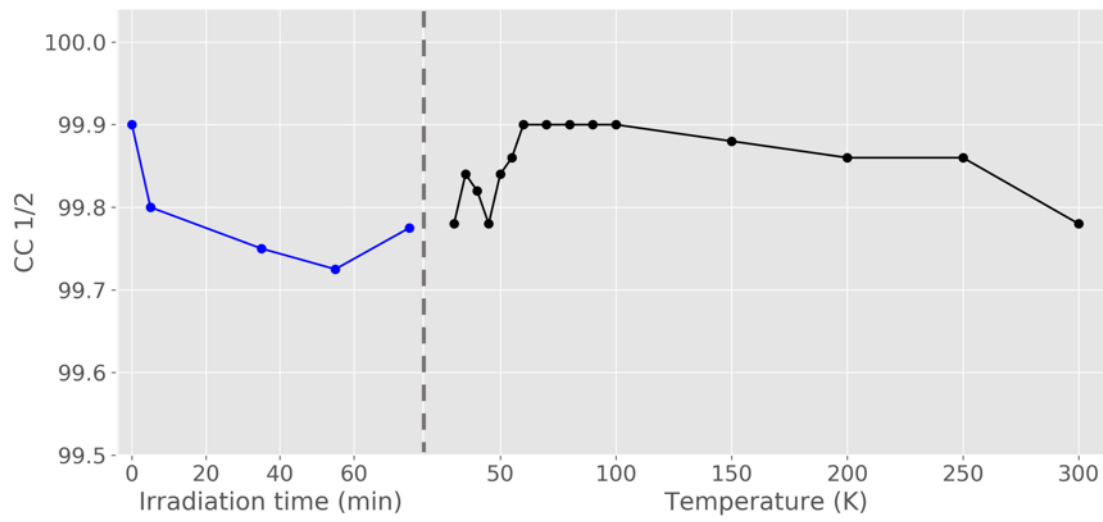

(c)

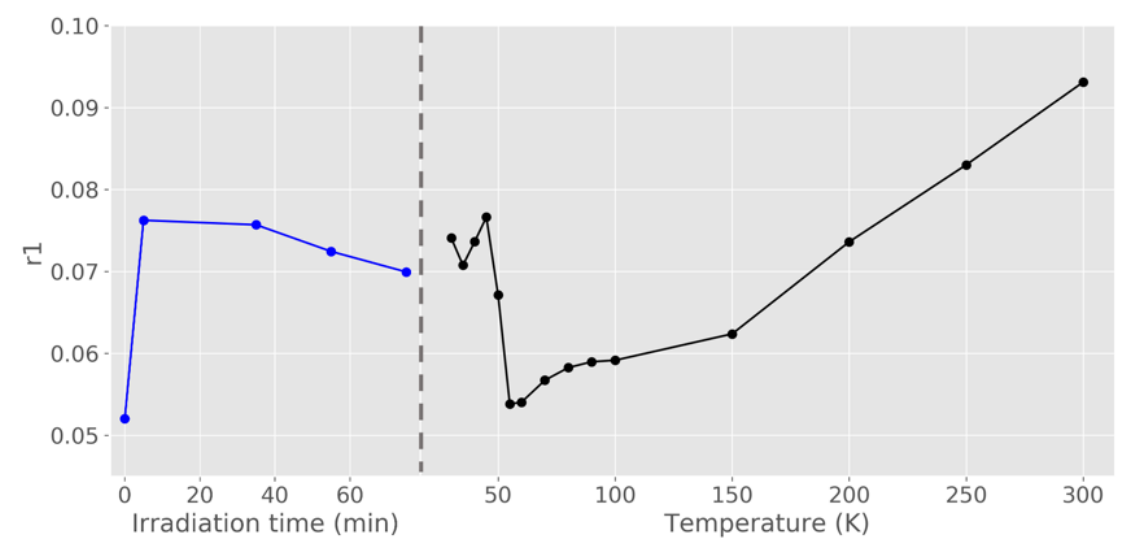


FIGURE S3. Crystal 3, experiment lightinduce_5: VT induced by X-rays, blue $450 \mathrm{~nm}$ light (0-30 min) and deexcitation of metastable states by red $660 \mathrm{~nm}$ light $(30-60 \mathrm{~min})$. The evolution of the statistics of the X-ray diffraction data and refinement for the crystals 1,2 and 3. (a) I/sigma, (b) cc1/2, (c) r1.

(a)

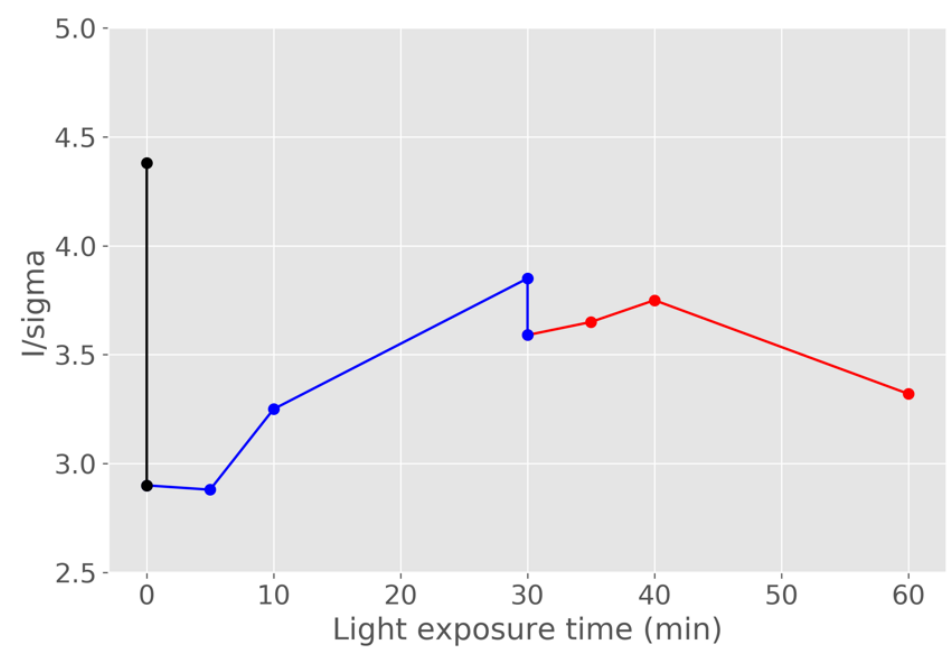

(b)

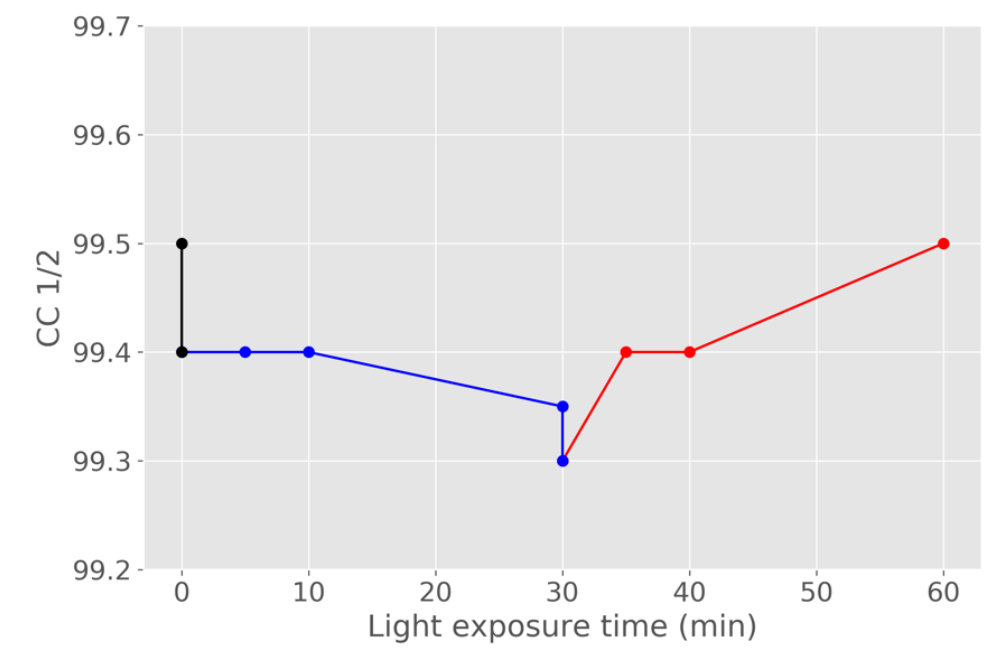

(c)

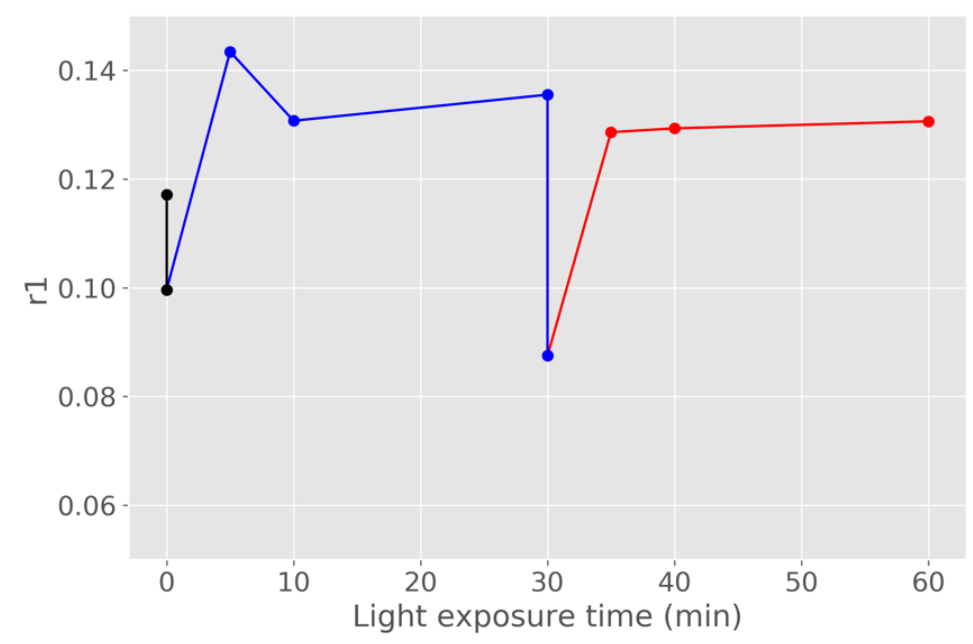


Table S3: Bond lengths between Co-N, Co-O and C-O for Crystal 1, experiment xrayinduce_1.

1. Metal-O/N bond lengths $[\AA]$.

\begin{tabular}{ll}
\hline $\mathrm{C}(1)-\mathrm{O}(1)$ & $1.329(3)$ \\
$\mathrm{C}(2)-\mathrm{O}(2)$ & $1.329(2)$ \\
$\mathrm{N}(1)-\mathrm{Co}$ & $1.9569(19)$ \\
$\mathrm{O}(1)-\mathrm{Co}$ & $1.8842(17)$ \\
$\mathrm{O}(2)-\mathrm{Co}$ & $1.885(3)$
\end{tabular}

2. Hydrogen bonds $\left[\AA\right.$ and $\left.^{\circ}\right]$.

\begin{tabular}{lcccc}
\hline $\mathrm{D}-\mathrm{H} \ldots \mathrm{A}$ & $\mathrm{d}(\mathrm{D}-\mathrm{H})$ & $\mathrm{d}(\mathrm{H} \ldots \mathrm{A})$ & $\mathrm{d}(\mathrm{D} \ldots \mathrm{A})$ & $<(\mathrm{DHA})$ \\
\hline $\mathrm{C}(15)-\mathrm{H}(15) \ldots \mathrm{O}(1)$ & 0.95 & 2.32 & $2.820(3)$ & 111.9 \\
$\mathrm{C}(16)-\mathrm{H}(16) \ldots \mathrm{O}(2) \# 2$ & 0.95 & 2.30 & $3.215(3)$ & 160.8 \\
$\mathrm{C}(18)-\mathrm{H}(18) \ldots \mathrm{N}(2) \# 3$ & 0.95 & 2.48 & $3.414(4)$ & 168.1 \\
$\mathrm{C}(19)-\mathrm{H}(19) \ldots \mathrm{O}(1) \# 1$ & 0.95 & 2.41 & $2.857(3)$ & 108.5
\end{tabular}

Symmetry transformations used to generate equivalent atoms:

\#1 -x,-y+1,-z+1; \#2 x,y,z+1; \#3 x,-y+1/2,z-1/2

Table S4: Bond lengths between $\mathrm{Co}-\mathrm{N}, \mathrm{Co}-\mathrm{O}$ and $\mathrm{C}-\mathrm{O}$ for Crystal 2, experiment lightinduce_3 and tempinduce_1 1. Metal-O/N bond lengths $[\AA]$.

\begin{tabular}{ll}
\hline $\mathrm{C}(1)-\mathrm{O}(1)$ & $1.326(3)$ \\
$\mathrm{C}(2)-\mathrm{O}(2)$ & $1.328(2)$ \\
$\mathrm{N}(1)-\mathrm{Co}$ & $1.958(2)$ \\
$\mathrm{O}(1)-\mathrm{Co}$ & $1.886(2)$ \\
$\mathrm{O}(2)-\mathrm{Co}$ & $1.884(3)$
\end{tabular}

2. Hydrogen bonds [ $\left[\AA\right.$ and $^{\circ}$ ].

\begin{tabular}{lcccc}
\hline D-H...A & d(D-H) & d(H...A) & d(D...A) & $<($ DHA $)$ \\
\hline $\mathrm{C}(15)-\mathrm{H}(15) \ldots \mathrm{O}(1)$ & 0.95 & 2.32 & $2.820(3)$ & 111.9 \\
$\mathrm{C}(16)-\mathrm{H}(16) \ldots \mathrm{O}(2) \# 2$ & 0.95 & 2.30 & $3.212(3)$ & 160.7 \\
$\mathrm{C}(18)-\mathrm{H}(18) \ldots \mathrm{N}(2) \# 3$ & 0.95 & 2.47 & $3.404(5)$ & 167.8 \\
$\mathrm{C}(19)-\mathrm{H}(19) \ldots \mathrm{O}(1) \# 1$ & 0.95 & 2.41 & $2.858(4)$ & 108.6
\end{tabular}

Symmetry transformations used to generate equivalent atoms:

\#1 -x,-y+1,-z+1; \#2 x,y,z+1; \#3 x,-y+1/2,z-1/2.

Table S5: Bond lengths between Co-N, Co-O and C-O for Crystal 3, experiment lightinduce_5

1. Metal-O/N bond lengths $[\AA]$.

\begin{tabular}{ll}
\hline $\mathrm{C}(1)-\mathrm{O}(1)$ & $1.345(7)$ \\
$\mathrm{C}(2)-\mathrm{O}(2)$ & $1.336(7)$ \\
$\mathrm{N}(1)-\mathrm{Co}$ & $1.957(6)$ \\
$\mathrm{O}(1)-\mathrm{Co}$ & $1.888(6)$ \\
$\mathrm{O}(2)-\mathrm{Co}$ & $1.896(7)$
\end{tabular}

2. Hydrogen bonds $\left[\AA\right.$ and $\left.^{\circ}\right]$.

\begin{tabular}{lcccr}
\hline D-H...A & d(D-H) & $d(H \ldots A)$ & $d(D \ldots A)$ & $<(D H A)$ \\
\hline $\mathrm{C}(15)-\mathrm{H}(15) \ldots \mathrm{O}(1)$ & 0.95 & 2.34 & $2.832(9)$ & 112.0 \\
$\mathrm{C}(16)-\mathrm{H}(16) \ldots \mathrm{O}(2) \# 2$ & 0.95 & 2.32 & $3.232(11)$ & 161.1 \\
$\mathrm{C}(18)-\mathrm{H}(18) \ldots \mathrm{N}(2) \# 3$ & 0.95 & 2.50 & $3.433(12)$ & 168.2 \\
$\mathrm{C}(19)-\mathrm{H}(19) \ldots \mathrm{O}(1) \# 1$ & 0.95 & 2.44 & $2.877(10)$ & 108.0
\end{tabular}

Symmetry transformations used to generate equivalent atoms:

\#1 -x,-y+1,-z+1; \#2 x,y,z+1; \#3 x,-y+1/2,z-1/2 


\section{Metrical oxidation state calculation for the dioxolene ligand}

The assignment of the oxidation state of the metal and ligand involved in the valence tautomerism of complexes with cathecolate as redox-active ligand can also be performed using the metrical oxidation state (MOS) calculation method proposed by Brown, $2012^{8}$. In such method, the distances between atoms within the ligands are considered instead of the metal- $\mathrm{L}$ distances ( $\mathrm{L}$ are all the atoms coordinated to the metal). The possible oxidation states of the dioxolene ligand are -2, -1 and 0, as shown in Figure S4. The calculation of the MOS for the dioxolene indirectly provides us with the oxidation state of the metal, once the total charge of the molecule does not change during the VT interconversion. The MOS method was used herein to support the results obtained in our work, in which we use solely the Metal-L distances to compute $h s-\mathrm{Co}^{\mathrm{II}}$ mole fraction as proposed by Ribeiro et al., $2016^{9}$.

For the $\left.\left[\mathrm{Co}(\text { diox })_{2}(4-\mathrm{CN}-\mathrm{py})_{2}\right)\right] \cdot$ benzene crystal, the VT transition reversibly assesses the $\left[h s-\mathrm{Co}^{+2}\left(\mathrm{SQ}^{*}\right)_{2}(4-\mathrm{CN}-\mathrm{py})_{2}\right]$ and $\left[l s-\mathrm{Co}^{+3}\left(\mathrm{Cat}^{2-}\right)\left(\mathrm{SQ}^{-}\right)(4-\mathrm{CN}-\mathrm{py})_{2}\right]$ states $\left(\mathrm{SQ}^{-}=\right.$semiquinone, $\mathrm{Cat}^{2-}=$ cathecolate $)$. In our work, the $\left[\mathrm{Co}(\text { diox })_{2}(4-\right.$ $\left.\mathrm{CN}-\mathrm{py})_{2}\right]$ · benzene crystalized in the monoclinic $P 2_{1} / c$ space group, with the Co atom sitting in a crystallographic center of inversion symmetry. Because of such, there is only one unique diox ligand for each complex molecule in the crystal structure and the $\mathrm{SQ}^{-}$and $\mathrm{Cat}^{2-}$ forms are superimposed in the high-spin state of the complex. Given this, the MOS calculation for our crystal structure should give MOS $=-1$ for the $h s-\mathrm{Co}^{\mathrm{II}}$ states, MOS $=[-1+(-2)] / 2=-1.5$ for the $l s-\mathrm{Co}^{\mathrm{III}}$ states, and values $-1.5 \leq$ MOS $\leq-1$ during the VT interconversion.

The MOS values as a function of X-ray and light exposure time, and temperature are shown in Figures S5, S6 and S7, bringing an immediate parallel to Figures $\mathbf{2 , 3}$ and $\mathbf{4}$ of the manuscript, respectively.

It is worth noting that for the X-ray VT induction test (Figures 2 and S5), the interconversion from $l s-\mathrm{Co}^{\mathrm{III}}$ to $h s-\mathrm{Co}^{\mathrm{II}}$ is negligible, and both mole fraction and MOS values fluctuate within their respective error.

FIGURE S4: Possible oxidation states of the cathecolate ligand $(\mathrm{E}=\mathrm{O})$. Reproduced from Brown, S. N. Inorg. Chem. 2012, 51 (3), 1251-1260. https://doi.org/10.1021/ic202764j ${ }^{8}$. Copyright () 2012 American Chemical Society.<smiles>[M]Oc1ccccc1F</smiles>

Catecholate or Amidophenoxide Ligand oxidation state $=-2$

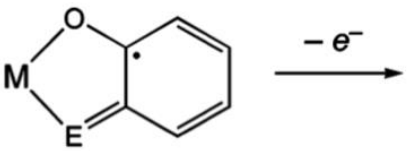

(Imino)semiquinone Ligand oxidation state $=-1$<smiles>[M]Oc1ccccc1</smiles>

(Imino)quinone Ligand oxidation state $=0$ 
FIGURE S5: MOS for the dioxolene ligand during the X-ray exposure when testing the X-ray induced VT at $30 \mathrm{~K}$ during SCXRD experiments with the $\left.\left[\mathrm{Co}(\text { diox })_{2}(4-\mathrm{CN}-\mathrm{py})_{2}\right)\right] \cdot$ benzene crystal. The blue, grey and green shaded regions correspond respectively to time intervals in which the crystal was exposed to $0.25,1$ and 0.6 transmission of the X-ray beam.

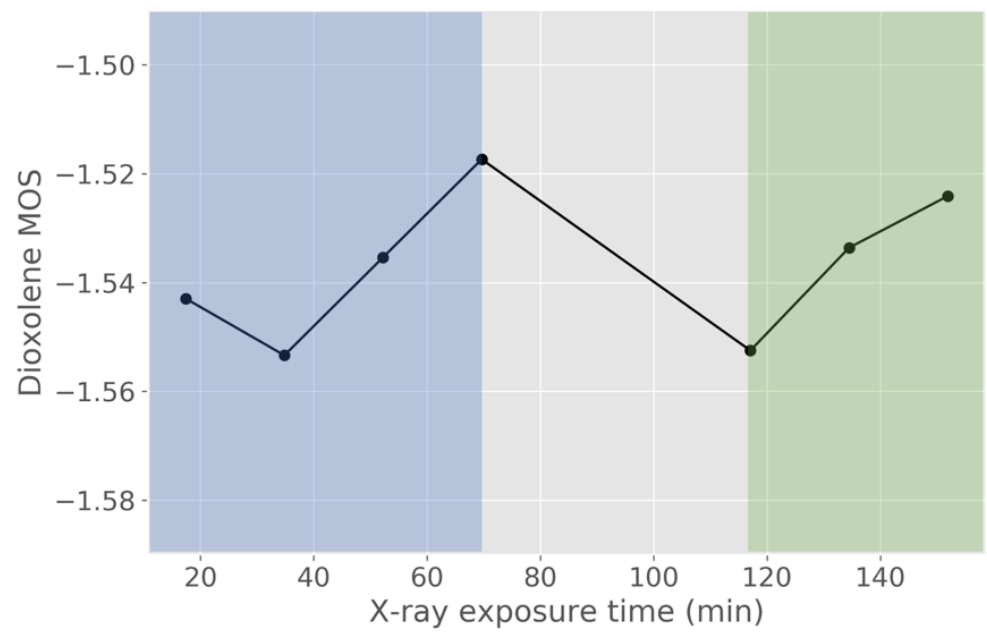

FIGURE S6: $\mathrm{MOS}$ for the dioxolene ligand of the in the $\left.\left[\mathrm{Co}(\operatorname{diox})_{2}(4-\mathrm{CN}-\mathrm{py})_{2}\right)\right]$-benzene crystal when exposed to blue $450 \mathrm{~nm}$ illumination (blue points) and to an increase in temperature (black points).

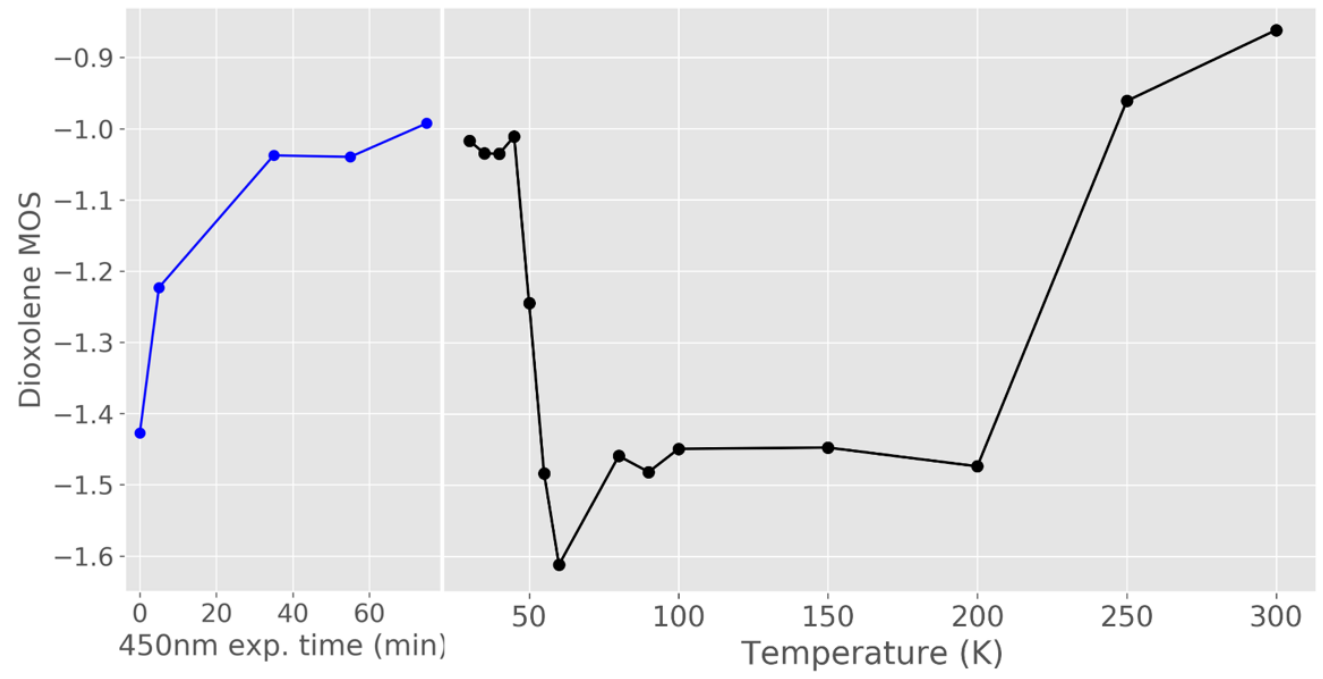

FIGURE S7: MOS for the dioxolene ligand in an SCXRD experiment with no light (gray region), during blue $450 \mathrm{~nm}$ light irradiation (blue region), with subsequent $660 \mathrm{~nm}$ irradiation (red region) as a function of time for the $\left[\mathrm{Co}(\operatorname{diox})_{2}(4-\right.$ CN-py) $\left.)_{2}\right)$ · benzene crystal at $30 \mathrm{~K}$.

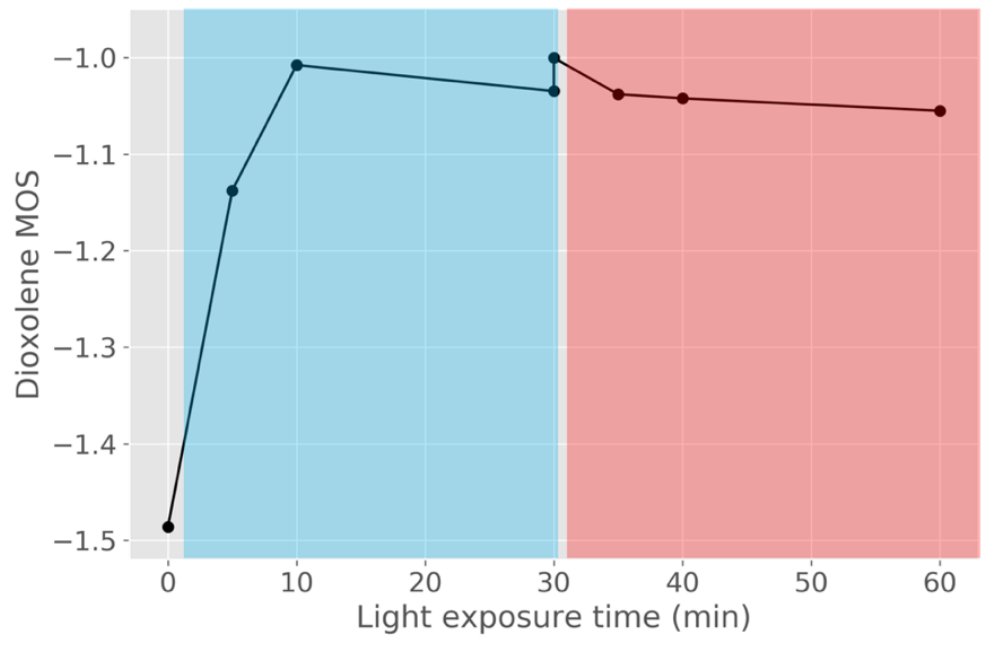




\section{Laser diodes technical specifications}

Table S6: minimum and maximum wavelength for L450P1600MM.

\begin{tabular}{lccc}
\hline \multirow{2}{*}{ Diode specification } & \multicolumn{3}{c}{ Peak Wavelength $(\mathbf{n m})$} \\
\cline { 2 - 4 } & Min & Typ. & Max \\
\hline L450P1600MM & 440 & 450 & 460 \\
\hline L660P120 & 652 & 660 & 665 \\
\hline
\end{tabular}

FIGURE S8: Temperature dependent spectrum of the blue laser diode L450P1600MM (source: ThorLabs Inc., Newton, New Jersey, USA).

\section{L450P1600MM Optical Spectrum}

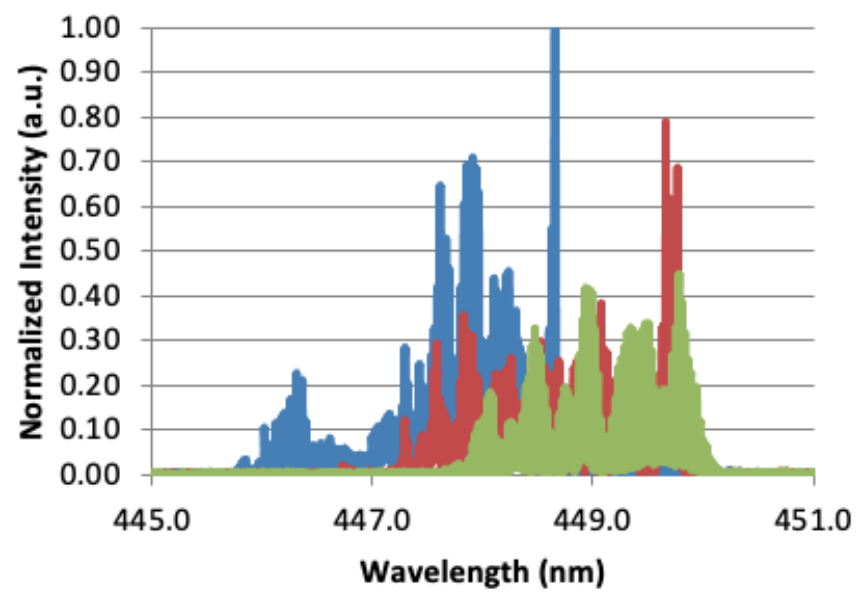

Normalized Intensity (a.u.) $10^{\circ} \mathrm{C}$

Normalized Intensity (a.u.) $25^{\circ} \mathrm{C}$

Normalized Intensity (a.u.)

$40^{\circ} \mathrm{C}$ 


\section{References}

(1) Kabsch, W. Xds. Acta Crystallogr. D Biol. Crystallogr. 2010, 66 (2), 125-132.

(2) Sheldrick, G. M. SHELXT-Integrated Space-Group and Crystal-Structure Determination. Acta Crystallogr. Sect. Found. Adv. 2015, 71 (1), 3-8.

(3) Sheldrick, G. M. Crystal Structure Refinement with SHELXL. Acta Crystallogr. Sect. C Struct. Chem. 2015, 71 (1), 3-8.

(4) Johnson, C. K. Introduction to Thermal- Motion Analysis. In Crystallographic Computing Proceedings of an international Summer School; Ahmed, F. R., Hall, S. R., Huber, C. P., Eds.; Munksgaard, Copenhagen: Ottawa, 1970; pp 207-219.

(5) Allen, F. H. The Cambridge Structural Database: A Quarter of a Million Crystal Structures and Rising. Acta Crystallogr. B 2002, 58 (3), 380-388.

(6) Karplus, P. A.; Diederichs, K. Linking Crystallographic Model and Data Quality. Science 2012, 336 (6084), $1030-1033$.

(7) Giacovazzo, C. Fundamentals of Crystallography, 2nd ed.; Giacovazzo, C., Ed.; IUCr texts on crystallography; Oxford University Press, 2002.

(8) Brown, S. N. Metrical Oxidation States of 2-Amidophenoxide and Catecholate Ligands: Structural Signatures of Metal-Ligand $\pi$ Bonding in Potentially Noninnocent Ligands. Inorg. Chem. 2012, 51 (3), 1251-1260.

(9) Ribeiro, M. A.; Stasiw, D. E.; Pattison, P.; Raithby, P. R.; Shultz, D. A.; Pinheiro, C. B. Toward Controlling the Solid State Valence Tautomeric Interconversion Character by Solvation. Cryst. Growth Des. 2016, 16 (4), 23852393. 